\title{
Work Stress, Coping Strategies and Levels of Depression among Nurs- es Working in Mental Health Hospital in Port-Said City
}

\author{
Abd Alhadi Hasan* \\ Department of Mental Health Nursing, Fakeeh College for Medical Sciences, Kingdom of Saudi Arabia \\ *Corresponding author: Abd Alhadi Hasan, Assistant professor, Department of Mental Health Nursing, Fakeeh College \\ for Medical Sciences, Palestine street, Jeddah, Kingdom of Saudi Arabia,E-mail: aalhasan@fakeeh.care
}

\begin{abstract}
Psychiatric nurses experience wide range of stressful events, evolving from the care of violent, aggressive patients, recurrent relapse episodes and poor prognosis of mental disorders; it affects several dimensions of nurses' life, physical and mental health. The aim of the study was to assess work stress, coping strategies and level of depression among psychiatric nurses. A descriptive correlation design was conducted on psychiatric nurses working in the mental health setting. Data were collected from 250 nurses working at mental health hospital in Port-Said city using self-report questionnaire and demographic characteristics. The results revealed that psychiatric nurses had moderate levels of work stress and depression, as well as exhibiting different coping strategies. In addition, there were statistically significant differences found in the experienced stress and depression level alongside utilized coping strategy in relation to nurse's demographic characteristics. Stress and depression are prevalent among psychiatric nurses in their work, thus, implementing programs aim at teaching psychiatric nurses how to deal with work stressors and raise their abilities regarding coping strategies and problem solving are recommended.
\end{abstract}

\section{Keywords}

Work stress, Coping, Depression, Psychiatric nurses

\section{Introduction}

\section{Work stress}

Work stress is a recognized as a major problem faces health care workers [1]. Nursing has been identified as an occupation with high levels of stress [2,3]. Nayomi [4] declares that stress involves an individual's perception of the demands and the available capability to han- dle this stressor. While, Kim and Lee [5] described occupational stress as any force moves a psychological or physical factor beyond its range of ability, thus it results with the strain.

In addition to the general stressors being reported by general nurses, working area as closed unitsare additional source of stress beside to high patient-acuity levels. Specifically, the characteristics of patients in these units can be extremely aggressive, violent, and unpredictable and danger to themselves or others [6]. Therefore, psychiatric nurses tend to have difficulty in obtaining positive outcomes from their work; this, in turn, may influence the sense of reward they experience. Moreover, one of the basic psychiatric nurses' roles is to protect patients and others from danger with limited action can be taken against patients [7]. As a result, they face a complex ethical dilemmas and confrontational attitudes toward psychiatric nursing. This finding asserted in the study of Fagin, et al. [8] who concluded that the levels of stress experienced by are enormous high. Another study conducted by Bannai and Tamakoshi [9] studied the frequency and impact of patients' suicide on American psychiatrists' personal and professional lives. The result showed that stress levels were the main the direct reason to experience post-traumatic stress symptoms among psychiatrists.

\section{Coping strategies}

Blonna [10] found that effective utilizing of coping mechanism interferes with the experienced level of stress. This means that a stress level can be reduced 
considerably if an individual knows how to cope with stressors. In addition, Cheng and Cheung [11] explained that explained that a person who has experienced a cluster of stressful life events would be able to cope successfully with life if he/she is able to modify coping strategy to match the demands of the situation.

Researchers view coping as ongoing strategies used in particularly stressful situations and focused on the multidimensionality of coping $[12,13]$.

Coping is also conceptualized as a multidimensional construct, which includes cognitive and behavioral efforts [14]. Although there are a variety of ways of coping, such as confrontation coping, distancing, seeking social support, accepting responsibility, avoidance, and religious coping $[12,15,16]$ researchers tend to dichotomize these coping strategies as active or passive, or emotion-focused versus problem-focused, especially when they examine the impact of coping on psychological health [17]. The coping strategy can determine one's outcomes in facing and handling a stressful situation and influence the level of general health state [18]. Uchino defined coping strategy as the ability of a person in changing cognitive and behavioral efforts to manage psychological stress. Uchino further explained that coping strategy frequently act as mediators in influencing one's level of stressors. For example, a person who has a higher level of perceived stress tends to have a lower level of coping strategy.

Even though stress is hardly to be eliminated in our daily life, a proper way of coping with stress can be practiced in order to reduce stress [19]. Tully [20] investigated the impacts of the utilized coping techniques on the degrees of distress perceived by nursing students during their psychiatric course training. The findings of Tully's study showed that students who employed ineffective coping techniques reported having high degrees of distress. Evans and Kelly [21] examined the stress and coping abilities among the nursing student in the hospital in Ireland and they explored the type of clinical and educational stress that students are exposed to, examining coping mechanisms adopted. In an effort to deepen into the whole realm of stress, they examined the emotions experienced by the students when faced with stress including a look at the personality factors the help the students during turbulent times. Thotis [22] further suggested that the use of effective coping mechanisms is in fact the determinant factor to alleviate the harmful effects of person's perceived stress and enhance their level of general health. Drawing a conclusion from the aforementioned literature, it is shown that an individual's coping strategy while facing stress or challenge situation in life would affect the person's general health. Moreover, a study of hospital nurses in Australia and New Zealand found that type of coping strategy was significantly associated with physical and mental health [23].
In the same context, Kravits, McAllister-Black, Grant, and Kirk [24] classified the effects of stress into four categories which are affective, cognitive, physical and behavioral. Those reflecting the affective responses may include anxiety, tension, anger, depression and apathy experienced by the individual. Further researches proved that stress that is not well managed can cause emotional and psychological problems such as frustration, low self-esteem, depression and anxiety. The high level of stress may cause negative effect on person's mental and physical health $[25,26]$.

\section{Depression}

The evidences highlighted that depression and stress are interrelated to each other. The overlapping symptoms of these psychological problems among psychiatric nurses can lead to a wide range of clinical and personal problems which negatively impact on the quality of care being provided to patients. Depression is an individual experience and a complex phenomenon. People disconnect from their internal and external worlds as the feeling of despair is dominant [27]. It has been demonstrated that workplace stress, emotional and physical exhaustion, feeling a lack of control, and ineffective coping as a predisposing factor to depression. So, it is not unusual that psychiatric nurses suffer from the depression episode twice the rate of the general population. Generally, the risk factors of depression being female [28,29], low self-worth/self-esteem [30,31], maladaptive coping strategy [32] stressful life events $[29,33]$ and work stress [28].

Another study reported that work stress in the psychiatric department was positively correlated with psychiatric nurse's depression level and negatively related to resourcefulness. This study concluded that the significant predictors of depression level among psychiatric nurse was experienced level of the work stress [34].

In the same context, previous studies have found that individuals with high level of work stress, who had less control, less support, or had to work on weekends, had worse physical and mental health, and were more depressed $[28,35]$. Studies focused on stress and depression in nurses found that the nurses' tension was positively correlated to their depression levels $[11,36,37]$.

\section{Significance of the study}

According to the Pike [38], the majority of nurses in mental health care setting experience signs of psychological disturbance, and $40 \%$ are classified as experience distress. Little is known about psychiatric nurses in Egypt mental health hospitals. Despite these significant and dangerous outcomes, studies into stress in mental health nursing are few, and studies specifically looking at acute mental health nurses are even fewer [39]. So, the fact that there is little known about stress in acute mental health inpatient nurses, and its dangerous effects on the nurses' health and their profession, 
made it a very significant topic. Since nurses are under considerable stress, their professional and social status should be taken into serious consideration; otherwise, nursing services may undergo total deterioration [40]. Nurses, when experiencing great stress, draw upon various coping strategies, and obviously, their manner of coping with stress influences the quality of their professional performance. Thus, it is essential to identify the various coping strategies nurses apply to reduce stress [41]. Based on the previous research, there are two justifications for conducting the current research. First, the present research explores, for the first time, the psychological status (stress level, depression level) among psychiatric nurses in Egypt. This, in turn, hinders the proper assessment of mental condition among psychiatric nurses'. Thus, it may underestimate the serious psychological problems which directly influence nurses and patients, if it is not detected and managed earlier. Second, this study also hopes to provide a guideline how psychiatric nurses can manage their feeling of stress or depression by identifying the utilized coping strategies and its relationship with depression and stress. The research on mental health nursing is limited by various methodological problems. These include small sample sizes, which limit generalization of the findings, the use of insufficient measures to be able to say anything meaningful about the sample and the lack of valid and reliable measures. However, this study had adequate power and utilized outcome measures which had established psychometric properties. In addition, there is paucity in studies which examined these variables in Middle-East countries.

\section{Aim of the Study}

To assess work stress, coping strategies and levels of depression among psychiatric nurses in Mental Health hospital at Port-Said city.

\section{Study questions}

1. What is the level of work stress and depression among psychiatric nurses?

2. What are the most and least utilizing coping strategies by psychiatric nurses?

3. What is the most and least stressful work events reported by the nurses?

4. Does demographic data of the nurses affect level of stress, depression and strategies of coping?

5. Is there a relationship among work stress, coping strategies and level of depression?

\section{Methods}

\section{Study design}

A descriptive correlational design was used to determine the relationships among perceived work stress, coping strategies and levels of depression among psy- chiatric nurses. Ethical approval was obtained from the Scientific and Research Committee in the University of Port Said and Ministry of Health.

\section{Sample}

A total number of 70 registered psychiatric nurses working in in-patient units agreed to participate on the study. A poster about study was displayed in the hospital wards, advertising study and requesting volunteers. Interested participants ( $n=96$ ) were received information package about study alongside verbal explanation. All participants were allotted adequate time to think about their participation, then 70 patients were returned signed consent form and completed outcome measures.

\section{Measures}

The participants completed three instruments:

Devilliers, carson and leary stress scale: It has 30 items, scoring on a 5-point Likert type items with of the lowest value (1) means and the highest score of 5-indicates extremely stressed. The range of possible scores ranges from 0-120. The Cronbach's coefficient of this scale is of 0.96 [42]. The items included (1) Having to deal with disturbed (2) Conflicts not being settled (3) Lack of positive feedback from supervisors within the organization and unpredictable patients.

Psych nurse methods of coping questionnaire: This scale identifies the type of Used in order to assess the degree to which various coping strategies were utilized by psychiatric nurses. It consists of 35 items scored on a 5-likert - type scale: 1 = never, 2 = rarely, 3 = occasionally, 4 = often, 5 = all the time. Cronbach's coefficient alpha was utilized to estimate the internal consistency reliability of the overall scale and of each subscale. The reliability coefficient alpha was 0.90 . In addition, the reliability coefficient alphas ranged from 0.67 to 0.78 [43]. For instance, the items were covered (1) By taking a moment away from it all to gather my thoughts (2) By being optimistic that everything will work out in the end.

Beck depression inventory (BDI): This scale was devised by Beck, Steer, and Brown [44] and was used to assess the severity of affective, behavioral, cognitive and somatic symptoms of depression. It includes 21 statements that cover items related to the basic symptoms of depression, such as hopelessness and irritability, feeling of guilt or feelings of being punished, as well as physical symptoms such as fatigue, weight loss, and lack of interest in sex. Each answer of the participants was scored on a Likert type scale ranging from 0 to 3. This scale has a good psychometric property in Arabic language 0.76 to 0.75 .

\section{Data analysis}

Data were analyzed using the Statistical Package for the Social Sciences (SPSS) version 23. Statistical signifi- 
Table 1A: Socio-demographic characteristics of the participants.

\begin{tabular}{|l|l|l|}
\hline $\begin{array}{l}\text { Socio-demographic } \\
\text { characteristics }\end{array}$ & $\begin{array}{l}\text { Frequency } \\
(\mathbf{N}=\mathbf{7 0})\end{array}$ & $\mathbf{\%}$ \\
\hline Age: & & 14.2 \\
\hline$\leq 20$ & 10 & 57.1 \\
\hline $20-30$ & 40 & 22.8 \\
\hline $31-40$ & 16 & 5.0 \\
\hline$\geq 40$ & 4 & \\
\hline Marital status: & & 57.1 \\
\hline Married & 40 & 28.5 \\
\hline Single & 20 & 4.2 \\
\hline Divorced & 3 & 10.0 \\
\hline Widow & 7 & \\
\hline Sex & & 37.1 \\
\hline Male & 26 & 62.9 \\
\hline Female & 44 & \\
\hline Level of education & & 28.5 \\
\hline School & 20 & 50 \\
\hline College & 35 & 21.4 \\
\hline University & 15 & 64.2 \\
\hline Work unit & & 21.4 \\
\hline Male & 45 & 14.4 \\
\hline Female & 15 & 14.4 \\
\hline Addiction & 10 & \\
\hline Shift & & \\
\hline Morning & 15 & \\
\hline Afternoon & 10 & \\
\hline Night & & \\
\hline & & \\
\hline
\end{tabular}

Table 1B: Socio-demographic characteristics of the participants.

\begin{tabular}{|l|l|l|}
\hline $\begin{array}{l}\text { Socio-demographic } \\
\text { characteristics }\end{array}$ & $\begin{array}{l}\text { Frequency } \\
(\mathbf{N}=\mathbf{7 0})\end{array}$ & $\%$ \\
\hline Working hours: & & \\
\hline$\leq 60$ & 40 & 57.1 \\
\hline $61-70$ & 20 & 28.5 \\
\hline$\geq 70$ & 10 & 14.4 \\
\hline Years of experience: & & \\
\hline$\leq 3$ & 45 & 64.2 \\
\hline $3-5$ & 10 & 14.4 \\
\hline $5.1-7$ & 12 & 17.1 \\
\hline$\geq 7$ & 3 & 4.2 \\
\hline
\end{tabular}

cance was set at $p<0.05$. Descriptive statistics such as frequency, mean value and standard deviation were used to analyze sociodemographic characteristics. The Pearson product-moment correlation test was used to examine the relationship between the working stress level and coping mechanism and depression level as well as socio-demographic characteristics. Stepwise multiple linear regressions was carried out to test variables that had significant correlations with working stress to determine the relative importance of the variables in contributing to variation in working stress level [45].

\section{Results}

About three quarters of the participants (57.1\%) aged between 20 to 30-years-old. In addition, more than half of the nurses (62.9\%) were females and married. Most respondents had graduated from the Technical Institute of Nursing (50.0\%), while only $21.4 \%$ were
Table 2: The most and least identified stressful events by the participants.

\begin{tabular}{|c|c|c|}
\hline Stress items & Mean & SD \\
\hline \multicolumn{3}{|l|}{ The most stressful events: } \\
\hline $\begin{array}{l}\text { Dealing with physical and verbal abuse from } \\
\text { patients or others }\end{array}$ & 2.83 & 0.39 \\
\hline Insufficient training to work with difficult patients & 2.16 & 1.00 \\
\hline Dealing with potentially suicidal patients & 2.13 & 1.19 \\
\hline $\begin{array}{l}\text { Having to deal with disturbed and } \\
\text { unpredictable patients }\end{array}$ & 2.12 & 1.35 \\
\hline $\begin{array}{l}\text { Having to meet the demands of too many } \\
\text { patients }\end{array}$ & 1.98 & 1.26 \\
\hline \multicolumn{3}{|l|}{ The least stressful events: } \\
\hline $\begin{array}{l}\text { Discrepancy between job description and } \\
\text { what are expected to do }\end{array}$ & 0.96 & 0.86 \\
\hline $\begin{array}{l}\text { Having to deal with colleagues who do not } \\
\text { do their share of workload }\end{array}$ & 1.09 & 0.89 \\
\hline $\begin{array}{l}\text { Dealing with disagreements within the team } \\
\text { about patients' treatment }\end{array}$ & 1.13 & 0.98 \\
\hline The lack of adequate financial reward for the job & 1.15 & 0.65 \\
\hline Not being notified of changes before they occur & 1.16 & 1.02 \\
\hline
\end{tabular}

graduated from Nursing Faculty. Almost two thirds of nurses $(64.2 \%)$ working in male units, and $21.4 \%$ working in female units (Table $1 \mathrm{~A}$ and Table 1B).

Table 2 represents that the most stress triggers among psychiatric nurses in the psychiatric setting. It indicates that the most perceived source of job stress for nurses was dealing with physical and verbal abuse from patients or others as the mean 2.83 showed. The variation among nurses regarding this stressor was the lowest as the SD of 0.396 . The second most perceived stressor was related to the insufficient training to work with psychiatric patients and having to deal with potentially suicidal patients a mean of 2.169.

On the other hand, the least perceived source of stress was the discrepancy between planned job description and the actual nurse's tasks as the mean of 0.969 and SD 0.865. In addition, another least source of stressors were unhelpful nurses and disagreements within the team about patients' treatment. The results obtained from the preliminary analysis of stress level showed that the majority of the respondents had classified the level of stress perceived in the psychiatric setting as a moderate level (67.7\%). However, only around $16 \%$ of the sample recognized working in the psychiatric setting as sever level. Followed by low and high levels (16.9\% and $15.4 \%$ respectively (Table 3$)$.

It can be seen from the data in Table 4 that the most utilized coping strategy with stressors was identified among psychiatric nurses is self-assurance that his/her job will be appreciated by others (mean \pm SD $=3.676 \pm$ 1.133). Followed by, having confidence in own abilities to do job well (mean $\pm S D=3.446 \$ 1,173$ ). Conversely, develop an individual plan was least coping strategy employed among participants with the mean of 2.292 and standard deviation of 1.100 .

The results of the analysis showed that the average 
of depression level among participants was $23.903 \pm$ 9.062. Considering this variable, more than two-third of the participants were experienced a moderate level of depression $(81.6 \%)$ and the lowest percentage was reported mild level of depression (4.6\%) (Table 5).

The results of the correlational analysis revealed that there was a significant relationship between stress, coping strategies and levels of depression among psychiatric nurses. A significant relationship was detected between the perceived stress level and weather the participated used or not a coping mechanism (Pearson

Table 3: The intensity of the experienced working stress level by the participants.

\begin{tabular}{|l|l|l|}
\hline Levels of work stress & $\begin{array}{l}\text { Frequency } \\
(\mathbf{N}=\mathbf{7 0})\end{array}$ & $\%$ \\
\hline Mild & 13 & 18.5 \\
\hline Moderate & 23 & 32.8 \\
\hline Severe & 44 & 62.8 \\
\hline
\end{tabular}

Table 4: The most and least coping strategies utilized by the participants.

\begin{tabular}{|c|c|c|}
\hline & Mean & SD \\
\hline \multicolumn{3}{|l|}{ The most used coping strategies: } \\
\hline $\begin{array}{l}\text { Reminding self that the work she does will } \\
\text { be appreciated }\end{array}$ & 3.67 & 1.13 \\
\hline Having confidence in own abilities to do job well & 3.44 & 1.173 \\
\hline $\begin{array}{l}\text { Discussing with colleague's problems as } \\
\text { they arise at work }\end{array}$ & 3.44 & 1.1 \\
\hline $\begin{array}{l}\text { Coping through the satisfaction derived from } \\
\text { seeing a task through to completion }\end{array}$ & 3.44 & 1.18 \\
\hline By having a sense of usefulness and purpose & 3.36 & 1.16 \\
\hline \multicolumn{3}{|l|}{ The least used coping strategies: } \\
\hline $\begin{array}{l}\text { By making plans for myself that have } \\
\text { nothing to do with work }\end{array}$ & 2.29 & 1.10 \\
\hline By having a steady partner to turn to & 2.55 & 0.93 \\
\hline $\begin{array}{l}\text { By having a stable home life that is kept } \\
\text { separate from my work life }\end{array}$ & 2.56 & 1.18 \\
\hline Through having team supervision & 2.63 & 1.13 \\
\hline By venting to a friend or loved one & 2.66 & 1.18 \\
\hline
\end{tabular}

correlation $=0.651$ and $\mathrm{P}=0.01)$. In addition, there was positive significant correlation was detected between depression and stress level (Pearson correlation $=0.710$ and $P=0.01$ ), which reflects that when the level of experienced work stress increased, the level of depression is increased (Table 6).

Multiple regressions were performed in order to identify relationships among demographic characteristics and the three independent variables (stress level, depression level and coping strategies).

The results are shown in Table 7. In the model (1), working hours per week as a predictor variable, explained $32 \%$ of the variance in stress level $F[(2,12)=$ $4.901, P=0.011]$. However, yeas of experience were not statistically significant predictor for stress level $F(1,21)$ $=1.167, \mathrm{P}=0.033$. In model (2), marital status and working unit, years of experiences were significant predictors of the using effective coping strategies accounting for $67 \%$ of the variance in the depression level $F(3,32)$ $=8.722, \mathrm{P}<0.05$. A total of $78.5 \%$ of variance in depression level $F(3,14)=16.984$ was explained by age, level of education, shift and working hours per week.

\section{Discussion}

Nurses are the major force in hospitals and are often in the front line in contact with patients. Mental illness is a life-threatening condition and often results in social complications, which render nursing in inpatient psychiatry setting complex and challenging. Stress experienced at work by the psychiatric nurse is related to

Table 5: The experienced level of depression among the participants.

\begin{tabular}{|l|l|l|}
\hline Levels of depression & $\begin{array}{l}\text { Frequency } \\
\text { (N= 70) }\end{array}$ & \% \\
\hline Mild & 5 & 7.1 \\
\hline Moderate & 12 & 17.1 \\
\hline Severe & 53 & 75.7 \\
\hline
\end{tabular}

Table 6: Bivariate correlation coefficient between the occupation stress, coping strategies and depression among the psychiatric nurses.

\begin{tabular}{|l|l|l|l|l|l|l|}
\hline & \multicolumn{2}{l}{ Work stress } & \multicolumn{2}{l|}{ Coping strategies } & \multicolumn{2}{l|}{ Levels of depression } \\
\cline { 2 - 7 } & Pearson correlation & Sig. & Pearson correlation & Sig. & Pearson correlation & Sig. \\
\hline Work stress & - & - & -0.65 & 0.01 & 0.71 & 0.01 \\
\hline Coping strategies & -0.65 & 0.01 & - & - & -0.80 & 0.01 \\
\hline Levels of depression & 0.71 & 0.01 & -0.80 & 0.01 & - & - \\
\hline
\end{tabular}

Table 7: Stepwise multiple regression of the predictors of the occupation stress.

\begin{tabular}{|c|c|c|c|c|c|c|}
\hline \multirow[t]{2}{*}{ Nurses' demographic } & \multicolumn{2}{|c|}{$\begin{array}{l}\text { Model } 1 \\
\text { Occupation stress }\end{array}$} & \multicolumn{2}{|c|}{$\begin{array}{l}\text { Model } 2 \\
\text { Coping strategies }\end{array}$} & \multicolumn{2}{|c|}{$\begin{array}{l}\text { Model } 3 \\
\text { Depression }\end{array}$} \\
\hline & $\mathbf{F}$ & Sig & $\mathbf{F}$ & Sig & $\mathbf{F}$ & Sig \\
\hline Age & 3.717 & $0.016^{*}$ & 1.359 & 0.264 & 4.489 & $0.007^{*}$ \\
\hline Marital status & 3.142 & $0.032^{*}$ & 3.733 & $0.016^{*}$ & 1.149 & 0.337 \\
\hline Level of education & 3.449 & $0.038^{*}$ & 2.071 & 0.135 & 7.572 & $0.001^{*}$ \\
\hline Occupation unit & 11.181 & $0.000^{*}$ & 5.545 & $0.000^{*}$ & 1.485 & 0.209 \\
\hline Shift & 3.647 & $0.032^{*}$ & 2.188 & 0.121 & 4.261 & $0.019^{*}$ \\
\hline Occupation hours/week & 4.901 & $0.011^{*}$ & 0.335 & 0.717 & 0.662 & $0.050^{\star}$ \\
\hline Years of experience & 1.167 & 0.330 & 3.630 & 0.218 & 0.597 & 0.620 \\
\hline
\end{tabular}

${ }^{*} P<0.05$. 
several factors such as dealing with disturbed and unpredictable patients. The results of this study did show that coping mechanism did significantly influence stress and depression level among psychiatric nursing. Reduction in stress and depression level results from interaction between the stressors encountered during caregiving tasks and guided by their set of stress response and coping strategies. Moreover, empowering psychiatric nurses may have increased self-efficacy and reduced experienced psychological distress by improving coping strategies, making problematic behaviour more understandable and therefore, less psychochological distress experienced (stress and depression).

These results are in agreement with those obtained by Currid [39] who found that work stress significantly predicted depression level. Their coping abilities considered determinants to the extent in which stress can affect them. Thus, assessing work stress, strategies of coping and depression levels among nurses was the aim of the present study.

Concerning work stress, the present study revealed that two thirds of the nurses had a moderate level of stress, and the highest scores of stresses were frequently associated with patients' issues, while the lowest scores were related to the organizational issues. This may be explained by the fact that psychiatric patients often exhibit various types of symptoms with behavioral problems such as violence, agitation and suicide, long term exposure to such a stressful work environment can easily cause psychiatric nurses to suffer from stress responses. Consistently, Nayomi [4] illustrated that nurses who utilized ineffective coping techniques as secrecy, they were at higher risk to experience psychological distress compared with those used more effective coping strategy.

Additionally, the current study result was in line with Lateef, $\mathrm{Ng}$, and Anantharaman [46], who conducted a study on a sample of 80 emergency nurses, reported more than half of nurses had "moderate to extreme" level of stress and almost one-fifth of nurses experienced stress daily resulting from aggressive patient behavior, which was the most stressful experience. In Taif Governmental Hospital in Saudi Arabia a study conducted by Kamal, Al-Dhshan, Abu-Salameh, Abuadas, and Hassan [47] found that staff nurses were exposed to many types of job related stressors and from the most stressful categories were patient's demands.

Another stressor was identified in the present study is that variation between planned and actual nursing task, as they majority of the psychiatric nurses involved in many tasks were not related to the nursing which aggravated their stress level. It, in turn, led to depression. Similarly, Sørlie, Jansson, and Norberg; Sørlie, Kihlgren, and Kihlgren $[48,49]$ stated that nurses experienced troubled conscience when there was a discrepancy between their images of care and the reality of care. Moreover, the similar results were echoed in another study, wherein nurses perceived a conflict between the reality of in-patient care and their vision of psychiatric nursing [50].

But this result is not in line with White [6], who found that the highest scores of stress were related to staffing issues, while the lowest scores were related to patients' issues. Moreover, Edwards, Burnard, Coyle, Fothergill, and Hannigan [51] related sources of stress among psychiatric nurses to administration and organizational concerns. Moreover, HF Wang and Yeh; Yau, et al. $[52,53]$ found that high levels of occupational stress were related to workload. On the same context, W Wang, Kong, and Chair [54] added that workload, lack of support, inadequate preparation, and conflict with other nurses were the most frequent stressors experienced by Hong Kong nurses. Consistently, a study by Al-Aameri [55] aimed at assessing the most and least perceived sources of stress for nurses in Saudi public hospitals. The results show that organizational structure and climate, job itself, and managerial role are the most stressors mentioned by the nurses.

As regard coping strategies, this study showed that most of nurses reported that coping with stress by reminding self that the work will be appreciated, having confidence in own abilities to do job well and coping through the satisfaction derived from seeing a task through to completion. These strategies are concerned with positive attitudes towards self and work. This may be potentially explained by the fact that nursing is a remarkable profession, providing care to patients has its spiritual positive effect on nurses which enables them to provide the optimum care as they can. Another explanation is that coping by encouraging and reminding self that what we do will be appreciated, are utilized by most humans in the belief that God will reward us good for what we do well. This is in agreement with studies conducted in Muslim countries and mental health professional identified this as a coping strategy with work stress $[47,55]$.

Likewise, SM Wang, et al. [34] described that among the three frequently coping strategies used was positive thinking, positive outlook and positive comparisons. Moreover, McTiernan and McDonald [56] indicated that psychiatric nurses employ diverting attention and positive attitudes toward work strategies in coping with their daily work stressors. Also, Gholamzadeh, Sharif, and Dehghan Rad [57] reported that most nurses are trying to gain adaptation with their work tensions by believing in and feeling good about themselves; increasing knowledge and experience and relying on their abilities.

Conversely, White [6] contradicted this result by reporting that the least coping strategies often used by the psychiatric nurses working on locked units was 
diverting attention strategy. Edwards, et al.; Subhi AlZayyat and Al-Gamal [51,58] disagreed with the study result as they stated that problem focused strategy was the most utilizing coping strategy by nurses and social support was the least-used one. Furthermore, Deklava, Circenis, and Millere [59] revealed that the most coping strategies among nurses were problem solving and self-controlling.

Looking at the levels of depression among the studies nurses, the study showed that most of nurses had a moderate level. This may due to the previous results of the study which revealed that nurses had moderate levels of stress. Another reason mentioned by the participant's during data collection, is that life stressors, economic status and working for long time with depressed patients affect their mood and affect, also, relapse and long- term care of psychiatric patients are another reason for frustration and disappointments for them.

This result is in accordance with the results of Gong, et al.; Mark and Smith $[60,61]$ who demonstrated that depressive symptoms were not unusual among psychiatric nurses. One of the important findings of the study was the significant correlations detected among work stress, coping strategies and levels of depression. Strategies of coping were inversely correlated with work stress and depression, this may be because different stressful situations and depressive experiences may require different, multiple and renewable coping strategies. On the other hand, work stress and level of depression were correlated positively, this may be due to the fact that nurses-generally- and psychiatric nurses-specifically-facing everyday stressful events in work environment as dealing with excited, violent patients and workload caused by understaffing of nurses in the hospital. This, in turn, causes nurse to feel distressed. Long term stress is associated with depressive mood.

This is congruent with the study done by Moustaka and Constantinidis [62] on sources and effects of work related stress in nursing and reported that occupational stress consequently may cause mental problems such as anxiety, depression and feelings of inadequacy. In this respect, decreased using or maladaptive use of coping strategies had consistently been associated with poor mental health $[63,64]$. Moreover, utilizing different coping strategies found to buffers the effects of stress among mental health professionals [65-67]. In the same context, Yoshizawa, et al. [32] stated that the highest stress scores were correlated with the lowest coping skills scores.

In contrast, this result is incongruent with the study results of Lin, Probst and Hsu [68] who reported that coping behavior was not a significant moderator on the relationship between job stress and depression scores among psychiatric nurses. The present study revealed that there was a statistical significant difference be- tween demographics of the nurses and stress, as the stress scores were increased in nurses aged from 30 to 40-years-old, single, graduated from Technical Institute of Nursing, worked at female units, in morning shifts and working for more than 60 hours per week. This may be partially explained by the nature of individual characteristic that with advance age, person intends to be less adaptive to stressors.

In the line with this result, Yada, et al. [7] agreed with this result and found that nurses' stressors correlate significantly and positively with shift and level of education. In addition, Shen, Cheng, Tsai, Su-hsing, and Guo [69] reported that the occupational stress among psychiatric nurses in Taiwan was associated with young age, widowed, divorced, or separated marital status. Furthermore, Roche, Duffield, and White [70] found a positive relationship between the length of nurses' experience in psychiatric care and role competency. In the same context, Milutinović, Golubović, Brkić, and Prokeš [71] revealed that participants' age, marital status and education level were significantly impact on the perception of stress at work among nurses.

On the other hand, Al-Omar [72] was contradicted with this study result and mentioned that work stress was not influenced by the educational level, the gender and the marital status of nurses worked in Saudi hospitals. Interestingly, there was statistically significant differences were found between coping strategies and nurses' characteristics, predisposing that utilizing multiple coping strategies increased in nurses who were married, working at addiction unit and had years of experience more than 7 years. One of the potential explanation is that married persons face different life situations and responsibilities in their lives, teaching them how to cope with life stressors and experienced nurse may have develop their own coping strategies with stressors or may have higher stress threshold.

In keeping with previous studies, McTiernan and McDonald [56] inconsistent with the current study results, in which authors found that there were no significant influence of demographic variables as age, gender or grade in considering coping strategies. Moreover, Jose and Bhat [73] found that married nurses had lower coping skills. This variation from the current study might potentially attributed to the nature of Egypt psychiatric nurse culture "collectivistic" rather than "individualistic". There were statistically significant differences were noticed between depression and nurses' characteristics, predisposing that depression level increased in nurses who were aged more than 40-years-old, graduated from Nursing School and worked in night shift. The potential reasons for depression may be related to many responsibilities, lack of the scientific qualification or workload requiring close supervision during night shift.

Cheung and Yip [74] study confirmed this result as 
they stated that there were positive correlations between depression and divorce, widowhood and separation and job dissatisfaction. Also, Gong, et al. [60] observed that more than third of psychiatric nurses had depressive symptoms. It might be caused $b$ by frequent workplace violence, long working hours, recurrent night shifts. This finding was asserted by Bannai and Tamakoshi [9], who demonstrated a significant positive correlation between long working hours and frequent shift work with depressive symptoms.

\section{Conclusion and Recommendations}

The study results showed that stress and depression among psychiatric nurses working at Port-Said Mental Health hospital were moderate and associated with demographics as age, marital status, work unit and working hours, the study also revealed that most reported stressful events were related to patients' issues and more frequent coping strategies were concerned more with positive attitudes toward work and confidence in own abilities. Based on these findings it is recommended to implement programs aim at teaching psychiatric nurses how to deal with work stressors and its effects as well as enhance psychiatric nurses' abilities regarding coping strategies and problem solving.

\section{Ethics approval and consent to participate}

The ethical approval was obtained from the Ministry of Health in Jordan. In addition, Consent form was sought from all the study participants.

\section{Consent to publish}

I declare that all participants informed and consented such data are subjects for publication in psychiatry Journal.

\section{Availability of data and materials}

Data are available and ready upon request. Data are kept with the research team.

\section{Conflicts of interest}

The authors declare that they have no conflicts of interest.

\section{Funding}

This study was not received any fund.

\section{References}

1. Khamisa N, Oldenburg B, Peltzer K, llic D (2015) Work related stress, burnout, job satisfaction and general health of nurses. Int J Environ Res Public Health 12: 652-666.

2. R Burbeck, S Coomber, SM Robinson, C Todd (2002) Occupational stress in consultants in accident and emergency medicine: a national survey of levels of stress at work. Emerg Med J 19: 234-238.

3. Greenglass ER, Burke RJ (2001) Stress and the effects of hospital restructuring in nurses. Can J Nurs Res 33: 93108.
4. Nayomi W (2016) Workplace stress in nursing: a literature review. Journal of Social Statistics 3: 47-53.

5. Se Hyang Kim, Mi-Aie Lee (2014) Effects of emotional labor and communication competence on turnover intention in nurses. J Korean Acad Nurs Adm 20: 332-341.

6. Richard A White (2006) Perceived stressors, coping strategies, and burnout pertaining to psychiatric nurses working on locked psychiatric units. Master's Theses and Doctoral Dissertations 84.

7. Hironori Yada, Hiroshi Abe, Hisamitsu Omori, Yasushi Ishida, Takahiko Katoh (2009) Stressor among nurses in a psychiatric department--comparison between acute and recuperation wards. Journal of UOEH 31: 293-303.

8. Fagin L, Carson J, Leary J, De Villiers N, Bartlett H, et al. (2010) Stress, coping and burnout in mental health nurses: findings from three research studies. International Journal of Social Psychiatry 42: 102-111.

9. Bannai A, Tamakoshi A (2014) The association between long working hours and health: a systematic review of epidemiological evidence. Scand J Work Environ Health 40: 5-18.

10. Blonna R (2006) Coping with stress in a changing world: McGraw-Hill Humanities/Social Sciences/Languages.

11. Cheng C, Cheung MW (2005) Cognitive processes underlying coping flexibility: differentiation and integration. J Pers 73: 859-886

12. Richard S Lazarus, Susan Folkman (1984) Stress, appraisal and coping. Springer Publishing company, Newyork.

13. Miriam Schiff, Nabila El Bassel, Malitta Engstrom, Louisa Gilbert (2002) Psychological distress and intimate physical and sexual abuse among women in methadone maintenance treatment programs. Social Service Review 76: 302320.

14. JT Ptacek, Gregory R Pierce, John J Ptacek (2002) The social context of coping with prostate cancer. Journal of Psychosocial Oncology 20: 61-80.

15. F Ariff, A Suthahar, M Ramli (2011) Coping styles and lifestyle factors among hypertensive and non-hypertensive subjects. Singapore Medical Journal 52: 29-34.

16. Vitaliano PP, Russo J, Carr JE, Maiuro RD, Becker J (1985) The ways of coping checklist: Revision and psychometric properties. Multivariate Behav Res 20: 3-26.

17. Shirazi M, Khan MA, Khan RA (2011) Coping strategies: a cross-cultural study. Romanian Journal of Psychology, Psychotherapy and Neuroscience 1: 284-302.

18. Uchino BN (2004) Social support and physical health: Understanding the health consequences of relationships: Yale University Press.

19. Robin L Walton, Dennis P Prisk (2002) A comparison of perceived stress levels and coping styles of junior and senior students in nursing and social work programs. CiteSeer.

20. Tully A (2004) Stress, sources of stress and ways of coping among psychiatric nursing students. J Psychiatr Ment Health Nurs 11: 43-47.

21. Evans W, Kelly B (2004) Pre-registration diploma student nurse stress and coping measures. Nurse Educ Today 24: 473-482.

22. Thoits PA (1995) Stress, coping, and social support processes: Where are we? What next? J Health Soc Behav 53-79. 
23. Chang EM, Bidewell JW, Huntington AD, Daly J, Johnson A (2007) A survey of role stress, coping and health in Australian and New Zealand hospital nurses. Int J Nurs Stud 44: 1354-1362.

24. Kravits K, McAllister-Black R, Grant M, Kirk C (2010) Selfcare strategies for nurses: A psycho-educational intervention for stress reduction and the prevention of burnout. Appl Nurs Res 23: 130-138.

25. Esra Albal, Yasemin Kutlu (2010) The relationship between the Depression Coping Self-Efficacy level and perceived social support resources. Journal of Psychiatric Nursing 1: $115-120$

26. Seyedfatemi N, Tafreshi M, Hagani H (2007) Experienced stressors and coping strategies among Iranian nursing students. BMC Nurs 6: 11.

27. Bayram N, Bilgel N (2008) The prevalence and socio-demographic correlations of depression, anxiety and stress among a group of university students. Soc Psychiatry Psychiatr Epidemiol 43: 667-672.

28. Blackmore ER, Stansfeld SA, Weller I, Munce S, Zagorski BM, et al. (2007) Major depressive episodes and work stress: results from a national population survey. Am J Public Health 97: 2088-2093.

29. Kendler KS, Kuhn JW, Prescott CA (2004) Childhood sexual abuse, stressful life events and risk for major depression in women. Psychol Med 34: 1475-1482.

30. Samantha Reis, Brin FS Grenyer (2002) Pathways to anaclitic and introjective depression. Psychology and Psychotherapy: Theory, Research and Practice 75: 445-459.

31. Rebecca Schennach-Wolff, Markus Jäger, Florian Seemüller, Michael Obermeier, Thomas Messer, et al. (2009) Attitude towards adherence in patients with schizophrenia at discharge. Journal of Psychiatric Research 43: 1294-1301.

32. Kaori Yoshizawa, Norio Sugawara, Norio Yasui-Furukori, Kazuma Danjo, Hanako Furukori, et al. (2016) Relationship between occupational stress and depression among psychiatric nurses in Japan. Archives of Environmental \& Occupational Health 71: 10-15.

33. Cabrera OA, Hoge CW, Bliese PD, Castro CA, Messer SC (2007) Childhood adversity and combat as predictors of depression and post-traumatic stress in deployed troops. Am J Prev Med 33: 77-82.

34. Wang SM, Lai CY, Chang YY, Huang CY, Zauszniewski JA, et al. (2015) The relationships among work stress, resourcefulness, and depression level in psychiatric nurses. Arch Psychiatr Nurs 29: 64-70.

35. Kopp MS, Stauder A, Purebl G, Janszky I, Skrabski A (2008) Work stress and mental health in a changing society. Eur J Public Health 18: 238-244.

36. Chiang YM, Chang Y (2012) Stress, depression, and intention to leave among nurses in different medical units: Implications for healthcare management/nursing practice. Health Policy 108: 149-157.

37. Lee WH, Kim CJ (2006) The relationship between depression, perceived stress, fatigue and anger in clinical nurses. Taehan Kanho Hakhoe Chi 36: 925-932.

38. Geoff Pike, Jane Ball (2006) At breaking point?: a survey of the wellbeing and working lives of nurses in 2005. Royal College of Nursing.

39. Currid TJ (2008) The lived experience and meaning of stress in acute mental health nurses. Br J Nurs 17: 880884.
40. Grusi Farshi M, Moslemi M (2005) Investigate the relationship between burnout and coping techniques Nurses Kurdistan province. Quarterly Journal of Psychological Studies 1: 5 .

41. LaShonda Leigh Bare (2004) Factors that most influence job satisfaction among cardic nurses in an acute care setting. Theses, Dissertations and Capstones. Marshall University, USA, 322.

42. Fagin L, Carson J, Leary J, De Villiers N, Bartlett H, et al. (1996) Stress, coping and burnout in mental health nurses: findings from three research studies. Int $\mathrm{J}$ Soc Psychiatry 42: 102-111.

43. S McElfatrick, J Carson, J Annett, C Cooper, F Holloway, et al. (2000) Assessing coping skills in mental health nurses: Is an occupation specific measure better than a generic coping skills scale? Personality and Individual Differences 28: 965-976.

44. Beck AT, Steer RA, Brown GK (1996) Beck depression inventory-II. San Antonio 78: 490-498.

45. Field A (2009) Discovering Statistics Using IBM SPSS Statistics.

46. Lateef F, Ng A, Anantharaman V (2001) Stress among nurses in the emergency department. Singapore Nursing Journal 28: 22-26.

47. Samar M Kamal, Merfat I Al-Dhshan, Karima A Abu-Salameh, Fuad H Abuadas, Mohammed M Hassan (2012) The effect of nurses' perceived job related stressors on job satisfaction in Taif Governmental Hospitals in Kingdom of Saudi Arabia. Journal of American Science 8: 119-125.

48. Sørlie V, Jansson L, Norberg A (2003) The meaning of being in ethically difficult care situations in paediatric care as narrated by female Registered Nurses. Scand J Caring Sci 17: $285-292$

49. Sørlie V, Kihlgren A, Kihlgren M (2005) Meeting ethical challenges in acute nursing care as narrated by registered nurses. Nurs Ethics 12: 133-142.

50. Fourie WJ, McDonald S, Connor J, Bartlett S (2005) The role of the registered nurse in an acute mental health inpatient setting in New Zealand: Perceptions versus reality. Int J Ment Health Nurs 14: 134-141.

51. Edwards D, Burnard $P$, Coyle D, Fothergill A, Hannigan B (2000) Stress and burnout in community mental health nursing: a review of the literature. J Psychiatr Ment Health Nurs 7: 7-14.

52. Wang HF, Yeh MC (2005) Stress, coping, and psychological health of vocational high school nursing students associated with a competitive entrance exam. J Nurs Res 13: 106-116.

53. Yau SY, Xiao XY, Lee LY, Tsang AY, Wong SL, et al. (2012) Job stress among nurses in China. Appl Nurs Res 25: $60-64$.

54. Wang W, Kong AW, Chair SY (2011) Relationship between job stress level and coping strategies used by Hong Kong nurses working in an acute surgical unit. Appl Nurs Res 24: 238-243.

55. Al-Aameri AS (2003) Source of job stress for nurses in public hospitals. Saudi Med J 24: 1183-1187.

56. McTiernan K, McDonald N (2015) Occupational stressors, burnout and coping strategies between hospital and community psychiatric nurses in a Dublin region. J Psychiatr Ment Health Nurs 22: 208-218. 
57. Gholamzadeh S, Sharif F, Rad FD (2011) Sources of occupational stress and coping strategies among nurses who are working in Admission and Emergency Department in Hospitals affiliated to Shiraz University of Medical Sciences. Iran J Nurs Midwifery Res 16: 41-46.

58. Al-Zayyat AS, Al-Gamal E (2014) Perceived stress and coping strategies among Jordanian nursing students during clinical practice in psychiatric/mental health courses. Int $J$ Ment Health Nurs 23: 326-335.

59. Liana Deklava, Kristaps Circenis, Inga Millere (2014) Stress coping mechanisms and professional burnout among Latvian nurses. Procedia-Social and Behavioral Sciences 159: 261-267.

60. Gong Yanhong, Han Tieguang, Yin Xiaoxv, Yang Guoan, Zhuang Runsen (2014) Prevalence of depressive symptoms and work-related risk factors among nurses in public hospitals in southern China: a cross-sectional study. Nature Scientific Reports 4: 7109.

61. Mark G, Smith A (2012) Occupational stress, job characteristics, coping, and the mental health of nurses. $\mathrm{Br} \mathrm{J}$ Health Psychol 17: 505-521.

62. Eleni Moustaka, Theodoros C Constantinidis (2010) Sources and effects of Work-related stress in nursing. Health Science Journal.

63. Hätinen Marja, Mäkikangas Anne, Kinnunen Ulla, Pekkonen Mika (2013) Recovery from burnout during a oneyear rehabilitation intervention with six-month follow-up: Associations with coping strategies. International Journal of Stress Management 20: 364-390.

64. Catherine J Kilfedder, Kevin G Power, Tony J Wells (2001) Burnout in psychiatric nursing. JAN 34: 383-396.
65. Hughes $\mathrm{H}$, Umeh K (2005) Work stress differentials between psychiatric and general nurses. Br J Nurs 14: 802-808.

66. Jenkins R, Elliott $P$ (2004) Stressors, burnout and social support: nurses in acute mental health settings. J Adv Nurs 48: 622-631.

67. Ward L (2011) Mental health nursing and stress: maintaining balance. Int J Ment Health Nurs 20: 77-85.

68. Lin HS, Probst JC, Hsu YC (2010) Depression among female psychiatric nurses in southern Taiwan: main and moderating effects of job stress, coping behaviour and social support. J Clin Nurs 19: 2342-2354.

69. Shen HC, Cheng Y, Tsai PJ, Lee SH, Guo YL (2005) Occupational stress in nurses in psychiatric institutions in Taiwan. J Occup Health 47: 218-225.

70. Roche M, Duffield C, White E (2011) Factors in the practice environment of nurses working in inpatient mental health: A partial least squares path modeling approach. Int J Nurs Stud 48: 1475-1486.

71. Milutinović D, Golubović B, Brkić N, Prokeš B (2012) Professional stress and health among critical care nurses in Serbia. Arh Hig Rada Toksikol 63: 171-180.

72. Badran Abdulrahman Al-Omar (2003) Sources of work-stress among hospital-staff at the Saudi MOH. Econ \& Adm 17: 3-16.

73. TessyTreesa Jose, Sripathy M Bhat (2013) A descriptive study on stress and coping of nurses working in selected hospitals of Udupi and mangalore districts Karnataka, India. IOSR Journal of Nursing and Health Science 3: 10-18.

74. Cheung T, Yip PS (2015) Depression, anxiety and symptoms of stress among Hong Kong nurses: A cross-sectional study. Int J Environ Res Public Health 12: 11072-11100. 